\title{
Improved Dynamic Response of DC to DC Converter Using Hybrid PSO Tuned Fuzzy Sliding Mode Controller
}

\author{
R. Anand1, P. Melba Mary² \\ ${ }^{1}$ Department of EEE, National College of Engineering, Tirunelveli, India \\ ${ }^{2}$ VV College of Engineering, Tisaiyanvilai, India \\ Email: anandrb.pk@gmail.com
}

Received 23 March 2016; accepted 17 May 2016; published 20 May 2016

Copyright (C) 2016 by authors and Scientific Research Publishing Inc.

This work is licensed under the Creative Commons Attribution International License (CC BY). http://creativecommons.org/licenses/by/4.0/

c) (i) Open Access

\begin{abstract}
DC/DC switching converters are widely used in numerous appliances in modern existence. In this paper, the dynamic and transient response of phase shift series resonant DC/DC converter are improved using hybrid particle swarm optimization tuned fuzzy sliding mode controller under starting and load step change conditions. The aim of the control is to regulate the output voltage beneath the load change. The model of the hybrid particle swarm optimization tuned fuzzy sliding mode controller is implemented using Sim Power Systems toolbox of MATLAB SIMULINK. Performance of the proposed dynamic novel control under step load change condition is investigated.
\end{abstract}

\section{Keywords}

DC to DC Converter, Dynamic Response, Hybrid Particle Swarm Optimization, Ripple Voltage, Sliding Mode Controller

\section{Introduction}

There has been a growing demand for small power converters in portable applications. For example, the electronic cell systems such as laptops and PDAs require multiple control voltages to the various internal functional blocks and multiple converters specialized power to each functional block is frequently enforced [1]. With supply voltages in free fall, the current sucked by IC will be much higher due to the increased power requirements. Owing to these grounds such as the efficiency of the supply, regulation, ripple, response time, size and weight, prize, power bus architecture, etc., the probability of facing difficulties may be high for designers. Among this one of the difficult challenges is suppressing ripple in output voltage. Jifeng Han and Annette von 
Jouanne introduced interleaved discharging (ID) approach to suppress this ripple and dual series resonant converter using an active clamp mechanism was introduced by them. But the cost and size was seemed to be large due to inductors [2]. Proceeding with them PWM based SM voltage controller for all basic DC to DC converters was introduced. Equations for controlling and implementation of the PWM-based Sliding mode voltage controllers were derived in simple manner [3]. But the voltage deviation in dynamic load was high. To reduce the output ripple, some of topologies were developed to control the dc to dc converters [4]. But they were not in interest with dynamic response. To obtain a good dynamic response, many current mode controllers were developed like, feedback loop using hysteresis and proportional Integral algorithm [5], current mode PID controller [6], current mode controller in boost converter [7], average current mode controller [8], but they all had tedious mathematical equations to solve.

Ahmad Saudi Samosir and Abdul Halim Mohd Yatim were developed a new control technique to regulate the output voltage for synchronous buck DC-DC converter [9]. In order to obtain a good voltage recovery time a noise shaped synchronous buck DC-DC converters was introduced. They had reduced a voltage recovery time a lot but transient time at starting was high [10]. In order to reduce the ripple voltage at output an adaptive terminal sliding mode control strategy was given by Hasan Komurcugil. But the voltage recovery time was too high [11]. To improve the dynamic response, neural adaptive dynamic surface control based on finite time identifier was introduced. But they developed two different modes for input and load variation [12]. Then the full bridge dc/dc converter was controlled by model predictive control [13] and DC-DC buck converter was controlled by sliding mode controller [14] to get a good response. But the voltage recovery time was high. Doo-Yong Jung et al were introduced a circuit which performed soft switching at both buck and boost operation shown in Figure 1 [15].

In this paper, bidirectional DC to DC converter which was introduced in [15], is controlled by using Hybrid Particle Swarm Optimization (HPSO) tuned Fuzzy Sliding Mode Controller. Due to the proposed control scheme dc to dc converter produces low ripple. It is possible to produce constant voltage at change in load. In this paper Section 2 gives the sliding mode controller theory and Section 3 and Section 4 describes the significance of fuzzy logic controller and hybrid particle swarm optimization used in proposed topology. In Section 5 simulation and experimental results are discussed. Finally Section 6 concludes.

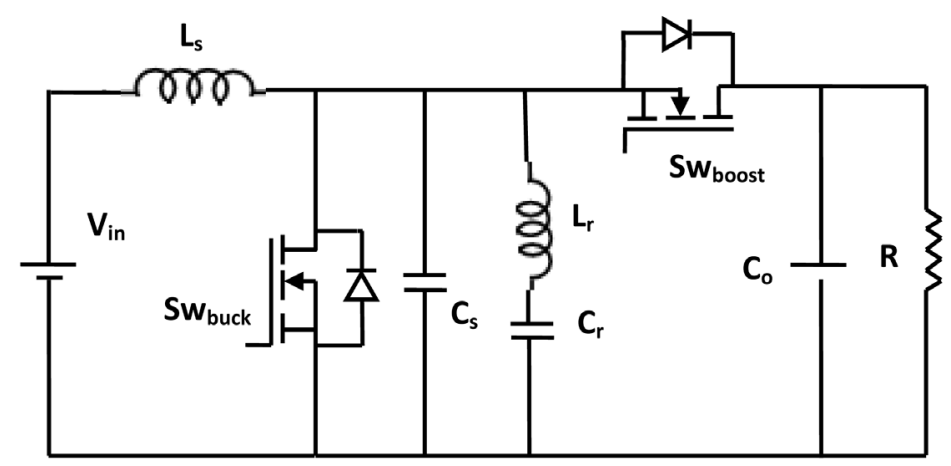

(a)

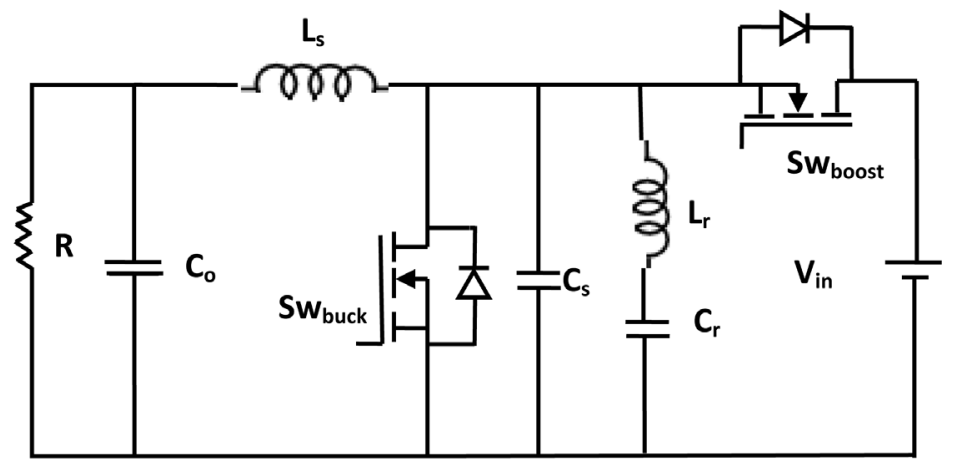

(b)

Figure 1. Bidirectional DC to DC converter (a) Boost converter (b) Buck converter. 


\section{Sliding Mode Controller}

Variable structure theory is considered as the base of sliding mode control. Sliding mode controller gives an admissible dynamic response and strength to the output response when sudden or huge variations of input and load variations. The system is enforced to be in the sliding surface custody, before that sliding mode controller is define the sliding surface including equilibrium point [14]. Switching is the prominent action for series resonant converters consequently sliding mode controller is a significant tool to control the chattering or ripple problem, seeing as control actions need continuously [16]. So as to identify the control tactic, first one has to launch the control objective; one of the vital control objectives is to maintain the voltage regulation under dynamic load conditions. One of the reservations is the load resistance " $\mathrm{R}$ " of the series resonant converter model which is shown in Figure 1, which may be cause to experience step variation. To survive with such a model uncertainty, the controller will be given an added flexible and adaptive potential. The control objective is to impose the output voltage to track a particular constant reference signal vd in spite of the system constraint reservations [17]. Owing to the robustness against the dynamics and parametric evaluation potential in the sliding mode controller is used in this paper. Three imperative steps involved in the design of sliding mode control and all are correlated, they are the picking of surface, the establishment of the invariance situations and resolve of the control law [18]. According to [18] and [19],

$$
\dot{x}=A(v, t)+B(v, t) u+d
$$

where,

$A, B$ are nonlinear functions of the state vector and the time, $d$ represent variations and $u$ is the control input.

Usually, we prefer a non-linear surface. The nonlinear structure is a function of the error on the controlled variable $(x)$, the sliding surface for second order systems is specified by,

$$
S(x)=\left(\frac{\mathrm{d}}{\mathrm{d} t}+\lambda_{x}\right)^{i-1} \cdot e(x)
$$

where, $e(x)$ is the error which is the difference between controlled variable and desired invariable

$$
e(x)=\dot{x}-x_{d}
$$

$\lambda_{x}$ is a positive invariable

$i$ is the iteration number to obtain the controlled surface.

The intention of the control is to keep up the error is zero. This is obtained by selecting a suitable choice of parameter $\lambda_{x}$ with respect to the meeting state. To obtain we have to provide to the surface a dynamic congregating to zero. This can be specified by

$$
\dot{S}(x) \cdot S(x)<0
$$

The positive scalar function is to make sure the pull the variable to be controlled to its orientation is known as Lyapunov function. We can define a Lyapunov function as,

$$
V(x)=\frac{1}{2} S^{2}(x)
$$

For a second order system,

$$
\begin{aligned}
& S(x)=\lambda e(x)+\dot{e}(x) \\
& \dot{S}(x)=\lambda \dot{e}(x)+\ddot{e}(x)
\end{aligned}
$$

The graceful form that can get the discrete control is as follows

$$
U=k_{s}(S) \cdot \operatorname{sign}(S(x, t))
$$

\section{Fuzzy in Sliding Mode Control}

Fuzzy controller can be replacing sliding mode controller with boundary layer. This estimates the control signal that depends on the space of the state vector from the sliding surface [19]. In case of $(8) k_{s}(S)$ is varied by fuzzy 
controller. When we use a Pulse Width Modulation there is a chance to occur a chattering. Here pulse width is changed by using a fuzzy sliding mode controller. The duty cycle is tuned along with the change of boundary layer due the rule base. In order to decrease the chattering the boundary layer should be varied. While we adjust the boundary layer, the parameters settling time and transient time will be affected. In order to satisfy all these constraints the sliding mode fuzzy controller is tuned [20]. Consequently, the membership function which is shown in Figure 2 and Equation (9) gives the entire rule base of this sort of fuzzy sliding mode controller.

If ( $s$ is $\mathrm{PB})$ then $(U$ is $\mathrm{NB})$.

If ( $s$ is $\mathrm{PM})$ then $(U$ is $N B)$.

If ( $s$ is PS) then ( $U$ is NM).

If $(s$ is $Z$ ) then ( $U$ is $N M)$.

If ( $s$ is NS) then ( $U$ is PM).

If ( $s$ is NM) then ( $U$ is $P B)$.

If ( $s$ is $N B)$ then $(U$ is $P B)$.

\section{Hybrid Particle Swarm Optimization}

In this paper the essential key factors for fuzzy sliding controller design are optimized by hybrid particle swarm optimization. In (6) the gain is optimized by hybrid particle swarm optimization (HPSO). Eberhart developed the optimization technique named as Particle Swarm Optimization (PSO). It is used to find its progress to the budding motion of a flock of birds seeking for food [21]. The subsequent points are the special features of particle swarm optimization technique. i) The technique is anchored in research on groups such as fish schooling and bird flocking. ii) Finding the particle velocity and revising its position are the only two steps of this technique. So computation time is very short [22].

In order to improve the computation time hybrid particle swarm optimization introduced in [23]. Every PSO iterations, velocity $v_{i j}$ and position vector particle $j$ of particle $i$ adjusted itself through each dimension $j$ by referring to, with random multipliers, the personal best vector $\left(\right.$ pbest $\left._{i j}\right)$ and the swarm's best vector $\left(\right.$ gbest $_{j}$, if the global version is adopted) [23] using Equations (10) and (11),

$$
\begin{gathered}
v_{i j, \text { new }}=w \cdot v_{i j}+c_{1} \operatorname{rand}_{1}\left(\text { pbest }_{i j}-d_{1} \cdot \text { particle }_{i j}\right)+c_{2} \operatorname{rand}_{2}\left(\text { gbest }_{i j}-d_{2} \cdot \text { particle }_{i j}\right) \\
\text { particle }_{i j, \text { new }}=\text { particle }_{i j}+v_{i j, \text { new }}
\end{gathered}
$$

where,

$c_{1}, c_{2}$ - cognitive coefficients

rand $_{1}$, rand $_{2}$-random real numbers drawn from $U(0,1)$.

$v_{i j}=$ velocity

particle $_{i j}=$ position vector

pbest $_{i j}=$ personal best vector

gbest $_{i j}=$ swarm's best vector

The following steps of the HPSO algorithm as [23] are used to optimize the gains of the Fuzzy SMC:

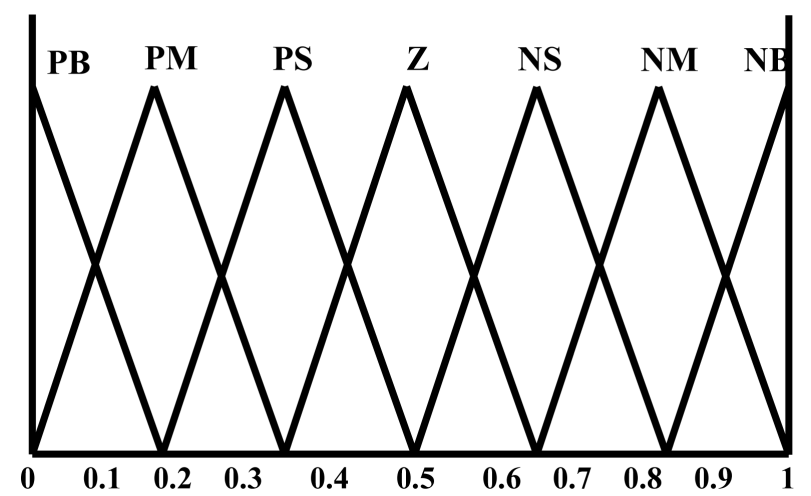

Figure 2. Membership functions. 
1. Initialize $K$ particles at random positions and velocities $v \mathrm{ij}, 1 \leq i \leq K$ and $1 \leq j \leq r$, is randomly drawn from $[0.0,1.0]$.

2. For every particle, evaluate the desired optimization fitness function.

3. Compare optimized fitness evaluation with pbest, which is the particle with best local fitness value.

4. Find the best vector gbest visited as far as this by the entire swarm.

5. By the use of Equation (9) renew velocities $v_{i j}$ with in the utmost threshold $v_{\max }$.

6. By the use of Equation (10) renew particles, vectors and improve the excellence of every particle.

7. Repeat step 2 until a solution is met.

\section{Simulation and Experimental Result Analysis}

The SIMULINK toolbox in the MATLAB software in order to model and test the dynamic response of DC to DC Converter using HPSO tuned Fuzzy Sliding Mode Controller. Simulation parameters are listed in table.

The Simulation block diagram of the DC to DC Converter using Hybrid PSO tuned Fuzzy Sliding Mode Controller is shown in Figure 3. The pulses given to the switches were controlled by the sliding mode controller. The formula was used for pulse generator input is,

$$
u=-K_{f u z z y} S(x) \cdot u_{o} \cdot|e(x)|
$$

where, $u_{o}$ is the initial value and $|e(x)|$ is the absolute value for error. With rule base (9) the simulation of fuzzy sliding mode controller based series resonant converter was carried out in MATLAB. The parameters of the DC to DC series converter are chosen to simulate according to Table 1. Hybrid particle swarm optimization was used to optimize the control gains which were used in the simulation of DC to DC Converter using HPSO tuned Fuzzy Sliding Mode Controller.

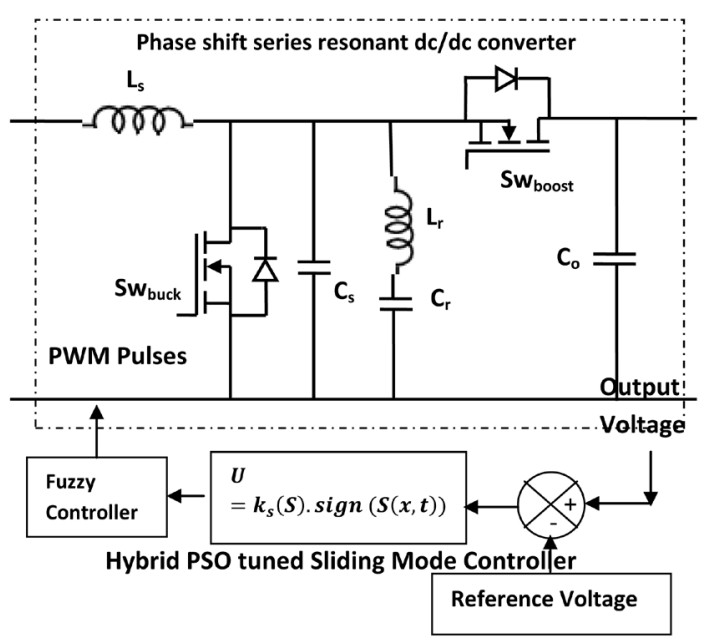

Figure 3. Simulation block diagram of the DC to DC converter using hybrid PSO tuned fuzzy sliding mode controller.

Table 1. Simulation parameters of DC to DC series converter.

\begin{tabular}{cc} 
Parameter & Value \\
\hline Source Inductor (Ls) & $0.007 \mu \mathrm{h}$ \\
Snubber Capacitor (Cs) & $33 \mathrm{nf}$ \\
Resonant Inductor (Lr) & $489 \mu \mathrm{h}$ \\
Resonant Capacitor (Cr) & $2 \mu \mathrm{f}$ \\
Output Capacitor (Co) & $52 \mathrm{mf}$ \\
Switching Frequency & $5 \mathrm{KHz}$
\end{tabular}


By considering bidirectional dc to dc converter as a boost converter, input voltage has given as $200 \mathrm{~V}$. The boost converter has been given $400 \mathrm{~V}$ output using fuzzy sliding mode controller gains which are tuned by using hybrid particle swarm optimization. The load has been changed from $50 \Omega$ to $33 \Omega$ at $0.1 \mathrm{Sec}$. the current has been changed but the voltage is maintained as constant are shown in Figure 4.

While we consider bidirectional dc to dc converter as a buck converter, input voltage has given as $400 \mathrm{~V}$. The buck converter has been controlled by using fuzzy sliding mode controller. The gains in the controller are tuned by using hybrid particle swarm optimization. The load has been changed from $100 \Omega$ to $50 \Omega$ at 0.1 Sec. Here the output voltage has maintained as constant by using controller at dynamic load condition which is shown in Figure 5. Table 2 and Table 3 provide the Comparison of recovery time, transient time and Ripple Voltage between proposed controller and other controllers.

Figure 6 gives the evaluation of performance of proposed controller and GA fuzzy PID controller. The simulation of GA Fuzzy PID DC to DC converter has carried out by using MATLAB simulink. Genetic algorithm is used to optimize the gains of Fuzzy PID controller. Genetic algorithm used in this paper has the following parameters: initial population of 150, number of generations 100, stochastic uniform selection, and reproduction with 8 elite individuals, Gaussian mutation with shrinking and scattered crossover.

To verify the strength of the proposed controller topology, a laboratory prototype rated to $0.25 \mathrm{kw}$ capacities is implemented. The components are selected to permit the dc to dc converter in the $0.25 \mathrm{kw}$ output range. Figure 7 shows the output voltages of the dc to dc converter when load changes 50 to 100 ohms. Output voltage ripple is controlled by hybrid PSO tuned fuzzy sliding mode controller. When load voltage changes from one value to another value, proposed controller reacts quickly and maintains the voltage as constant.
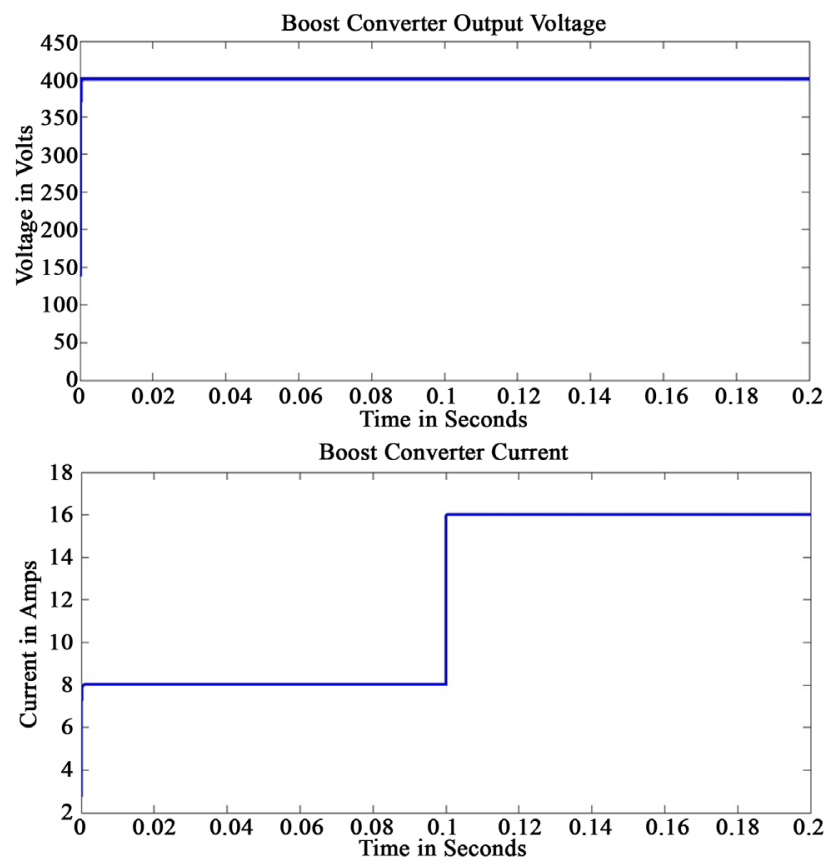

Figure 4. Output voltage and current waveform of boost converter at load change of $50 \Omega$ to $33 \Omega$.

Table 2. Comparison of recovery time and transient time between proposed controller and other controllers.

\begin{tabular}{ccc}
\hline Controller Type & Recovery Time & Transient Time \\
\hline Discretized sliding mode (DSM) control [24] & $3 \mathrm{~m} \mathrm{sec}$ & - \\
ATSMC [11] & $1.66 \mathrm{~m} \mathrm{sec}$ & $40 \mathrm{~m} \mathrm{sec}$ \\
SMC [11] & $38 \mathrm{~m} \mathrm{sec}$ & $60 \mathrm{~m} \mathrm{Sec}$ \\
GA Fuzzy PID & $1.2 \mathrm{~m} \mathrm{sec}$ & Buck converter $=17 \mathrm{~m} \mathrm{sec}$ \\
& & Boost Converter $=62 \mathrm{~m} \mathrm{sec}$ \\
PSO tuned Fuzzy Sliding Mode Controller & $0.4 \mathrm{~m} \mathrm{sec}$ & Buck converter $=16 \mathrm{~m} \mathrm{sec}$ \\
Boost Converter $=0.6 \mathrm{~m} \mathrm{sec}$
\end{tabular}




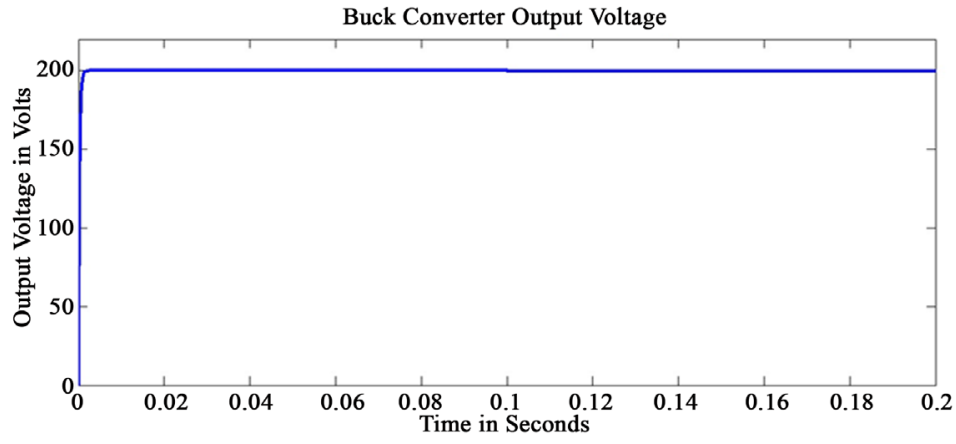

(a)

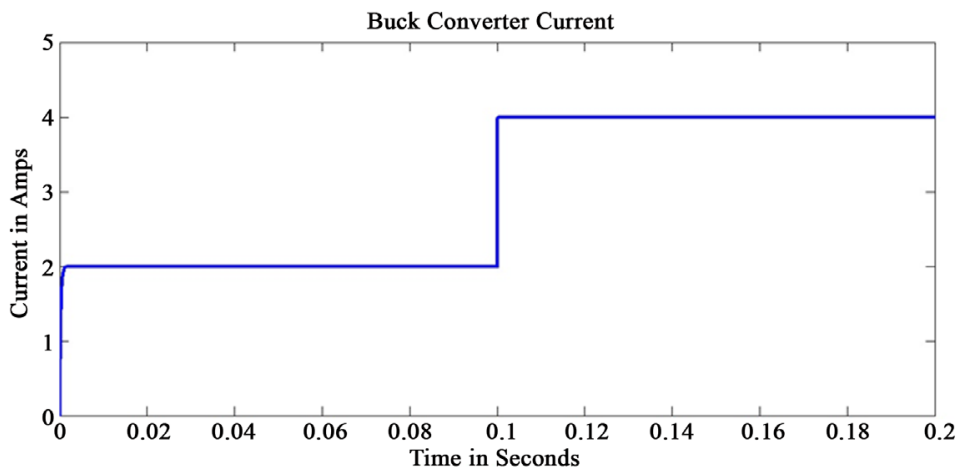

(b)

Figure 5. Output voltage and current waveform of buck converter at load change of $100 \Omega$ to $50 \Omega$.

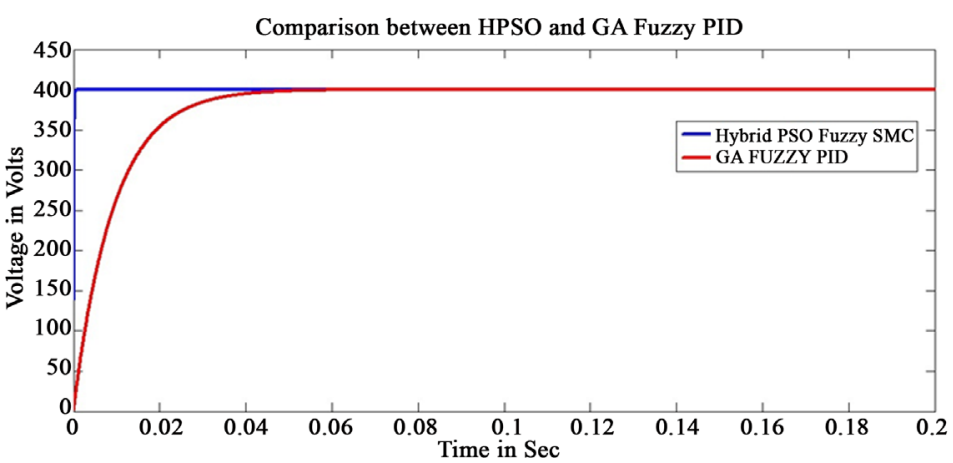

(a)

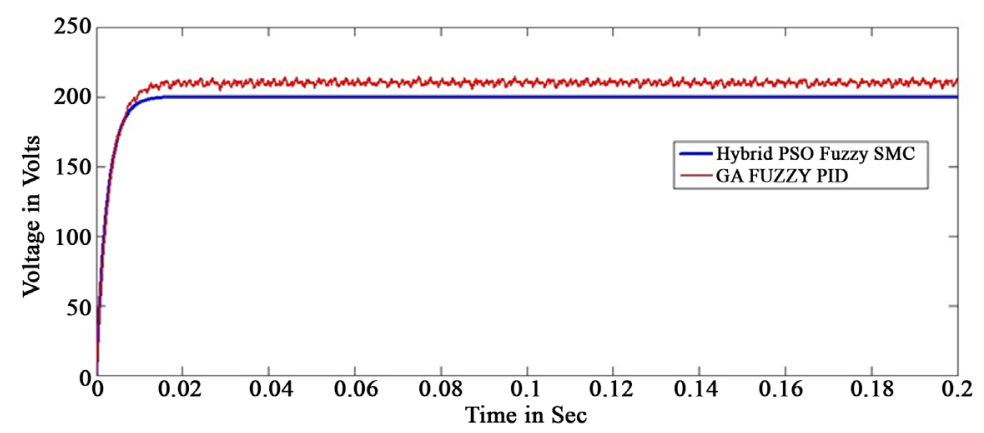

(b)

Figure 6. Comparison of output voltage of GA fuzzy PID DC to DC converter between Hybrid PSO fuzzy SMCDC to DC converter (a) Boost converter; (b) Buck converter. 


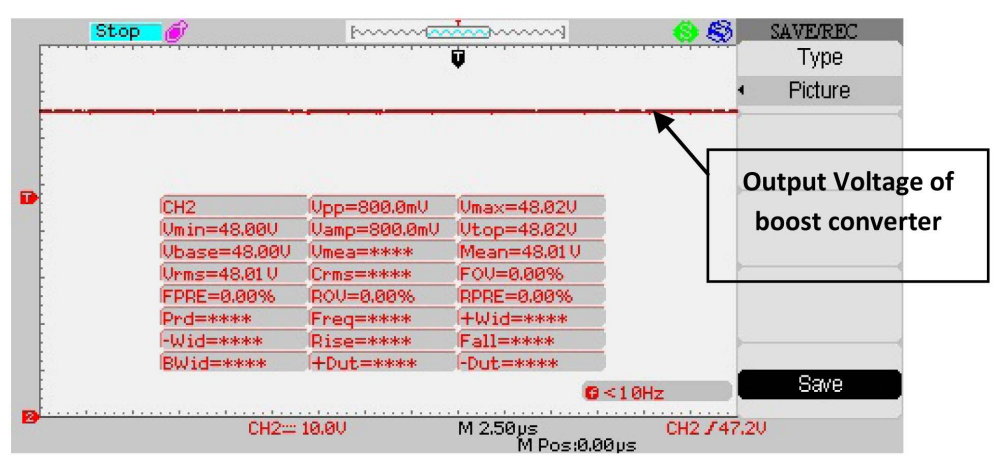

(a)

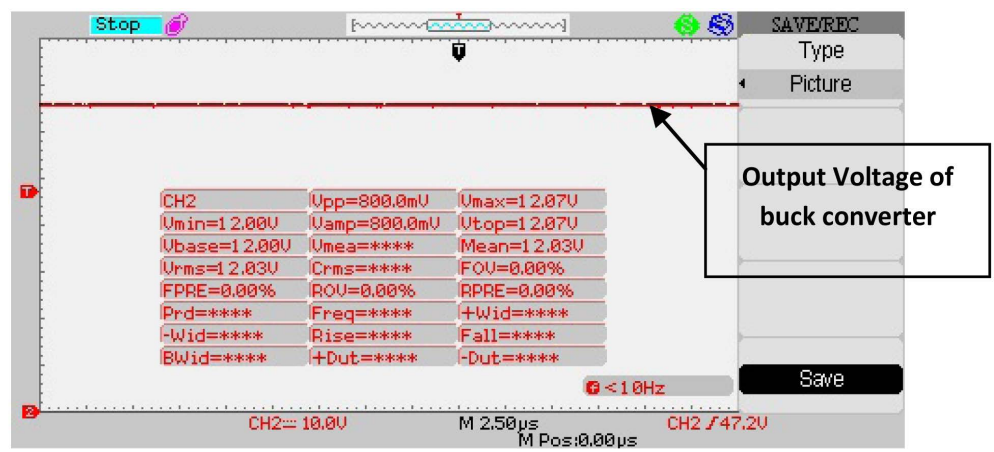

(b)

Figure 7. Results showing (a) Dynamic output voltage response of hybrid pso tuned fuzzy smc controlled boost dc to dc converter while input is $24 \mathrm{~V}$; (b) Dynamic output voltage response of hybrid pso tuned fuzzy smc controlled buck dc to dc converter while input is $24 \mathrm{~V}$.

Table 3. Comparison of ripple voltage between proposed controller and other controllers.

\begin{tabular}{cc}
\hline Controller Type & Voltage Ripple \\
\hline PWM-based SMVC boost converter. [3] & $840 \mathrm{mV}$ \\
Interleaved Discharging Method [2] & $24 \mathrm{mV}$ \\
GA Fuzzy PID & Buck converter $=9 \mathrm{~V}$ \\
& Boost Converter $=35 \mathrm{~m} \mathrm{~V}$ \\
PSO tuned Fuzzy Sliding Mode Controller & Buck converter $=7 \mathrm{~m} \mathrm{~V}$ \\
\hline
\end{tabular}

\section{Conclusion}

In this paper, a new configuration named DC to DC Converter using hybrid PSO tuned Fuzzy Sliding Mode Controller. The proposed topology has low ripple voltage at output. The new configuration is compared to existing DC to DC Converter topologies. The proposed topology is competent of fully protecting the DC to DC converter when load changing condition against ripple voltage. Comparison of recovery time, transient time and Ripple Voltage between proposed controller and other controllers are carried out. Because of the hybrid particle swarm optimization tuning the over shoot and ripple has been eliminated. The MATLAB/Simulink based simulation and experimental results confirms that the ripple voltage, recovery time while load changing and transient time has been absolutely improved.

\section{References}

[1] Park, J.-W. and Allen, M.G. (2003) Ultralow-Profile Micromachined Power Inductors with Highly Laminated Ni/Fe Cores: Application to Low-Megahertz DC-DC Converters. IEEE Transactions on Magnetics, 39, 3184-3186. http://dx.doi.org/10.1109/TMAG.2003.816051 
[2] Han, J.F., von Jouanne, A. and Temes, G.C. (2006) A New Approach to Reducing Output Ripple in Switched-Capacitor-Based Step-Down DC-DC Converters. IEEE Transactions on Power Electronics, 21, 1548-1555. http://dx.doi.org/10.1109/TPEL.2006.882973

[3] Tan, S.-C., Lai, Y.M. and Tse, C.K. (2006) A Unified Approach to the Design of PWM-Based Sliding-Mode Voltage Controllers for Basic DC-DC Converters in Continuous Conduction Mode. IEEE Transactions on Circuits and Systems, 53, 1816-1827. http://dx.doi.org/10.1109/TCSI.2006.879052

[4] Rivetta, C.H., Emadi, A., Williamson, G.A., Jayabalan, R. and Fahimi, B. (2006) Analysis and Control of a Buck DCDC Converter Operating With Constant Power Load in Sea and Undersea Vehicles. IEEE Transactions on Industry Applications, 42, 559-572. http://dx.doi.org/10.1109/TIA.2005.863903

[5] Feng, G., Meyer, E. and Liu, Y.-F. (2007) A New Digital Control Algorithm to Achieve Optimal Dynamic Performance in DC-to-DC Converters. IEEE Transactions on Power Electronics, 22, 1489-1498. http://dx.doi.org/10.1109/TPEL.2007.900605

[6] Choi, B., Kim, D., Lee, D., Choi, S. and Sun, J. (2007) Analysis of Input Filter Interactions in Switching Power Converters. IEEE Transactions on Power Electronics, 22, 452-460. http://dx.doi.org/10.1109/TPEL.2006.889925

[7] Lee, J.-J., Kwon, J.-M., Kim, E.-H. and Kwon, B.-H. (2008) Dual Series-Resonant Active-Clamp Converter. IEEE Transactions on Industrial Electronics, 55, 699-710. http://dx.doi.org/10.1109/TIE.2007.911912

[8] Choi, B., Lim, W., Choi, S. and Sun, J. (2008) Comparative Performance Evaluation of Current-Mode Control Schemes Adapted to Asymmetrically Driven Bridge-Type Pulsewidth Modulated DC-to-DC Converters. IEEE Transactions on Industrial Electronics, 55, 2033-2042. http://dx.doi.org/10.1109/TIE.2008.920582

[9] Samosir, A.S. and Yatim, A.H.M. (2010) Dynamic Evolution Control for Synchronous Buck DC-DC Converter: Theory, Model and Simulation. Simulation Modelling Practice and Theory, 18, 663-676.

[10] Yan, W., Li, W.H. and Liu, R. (2011) A Noise-Shaped Buck DC-DC Converter with Improved Light-Load Efficiency and Fast Transient Response. IEEE Transactions on Power Electronics, 26, 3908-3924. http://dx.doi.org/10.1109/TPEL.2011.2136361

[11] Komurcugil, H. (2012) Adaptive Terminal Sliding-Mode Control Strategy for DC-DC Buck Converters. ISA Transactions, 51, 673-681. http://dx.doi.org/10.1016/j.isatra.2012.07.005

[12] Chen, Q., Ren, X.M. and Oliver, J.A. (2012) Identifier-Based Adaptive Neural Dynamic Surface Control for Uncertain DC-DC Buck Converter System with Input Constraint. Communications in Nonlinear Science and Numerical Simulation, 17, 1871-1883. http://dx.doi.org/10.1016/j.cnsns.2011.08.028

[13] Xie, Y.H., Ghaemi, R., Sun, J. and Freudenberg, J.S. (2012) Model Predictive Control for a Full Bridge DC/DC Converter. IEEE Transactions on Control Systems Technology, 20, 164-172. http://dx.doi.org/10.1109/TCST.2011.2107575

[14] Bensaada, M. and Stambouli, B. (2013) A Practical Design Sliding Mode Controller for DC-DC Converter Based on Control Parameters Optimization Using Assigned Poles Associate to Genetic Algorithm. Electrical Power and Energy Sytems, 53, 761-773. http://dx.doi.org/10.1016/j.ijepes.2013.05.043

[15] Jung, D.-Y., Hwang, S.-H., Ji, Y.-H., Lee, J.-H., Jung, Y.-C. and Won, C.-Y. (2013) Soft-Switching Bidirectional DC/DC Converter with a LC Series Resonant Circuit. IEEE Transactions on Power Electronics, 28, 1080-1090. http://dx.doi.org/10.1109/TPEL.2012.2208765

[16] Utkin, V. (2013) Sliding Mode Control of DC/DC Converters. Journal of the Franklin Institute, 350, 2146-2165. http://dx.doi.org/10.1016/j.jfranklin.2013.02.026

[17] El Fadil, H., Giri, F. and Guerrero, J.M. (2010) Adaptive Sliding Mode Control of Interleaved Parallel Boost Converter for Fuel Cell Energy Generation System. Mathematics and Computers in Simulation, 91, 193-210. http://dx.doi.org/10.1016/j.matcom.2012.07.011

[18] Rekioua, D., Achour, A.Y. and Rekioua, T. (2013) Tracking Power Photovoltaic System with Sliding Mode Control Strategy. Energy Procedia, 36, 219-230. http://dx.doi.org/10.1016/j.egypro.2013.07.025

[19] Antic, D., Milojkovic, M., Jovanovic, Z. and Nikolic, S. (2010) Optimal Design of the Fuzzy Sliding Mode Control for a DC Servo Drive. Journal of Mechanical Engineering, 56, 455-463.

[20] Guo, L.P., Hung, J.Y. and Nelms, R.M. (2011) Comparative Evaluation of Sliding Mode Fuzzy Controller and PID Controller for a Boost Converter. Electric Power Systems Research, 81, 99-106. http://dx.doi.org/10.1016/j.epsr.2010.07.018

[21] Kannan, S.M., Renuga, P., Kalyani, S. and Muthukumaran, E. (2011) Optimal Capacitor Placement and Sizing Using Fuzzy-DE and Fuzzy-MAPSO Methods. Applied Soft Computing, 11, 4997-5005. http://dx.doi.org/10.1016/j.asoc.2011.05.058

[22] El-Zonkoly, A.M. (2011) Optimal Placement of Multi-Distributed Generation Units including Different Load Models 
Using Particle Swarm Optimization. Swarm and Evolutionary Computation, 1, 50-59. http://dx.doi.org/10.1016/j.swevo.2011.02.003

[23] Yin, P.-Y., Yu, S.-S., Wang, P.-P. and Wanxg, Y.-T. (2006) A Hybrid Particle Swarm Optimization Algorithm for Optimal Task Assignment in Distributed Systems. Computer Standards \& Interfaces, 28, 441-450. http://dx.doi.org/10.1016/j.csi.2005.03.005

[24] Maity, S. (2013) Dynamics and Stability Issues of a Discretized Sliding-Mode Controlled DC-DC Buck Converter Governed by Fixed-Event-Time Switching. IEEE Transactions on Circuits and Systems, 60, 1567-1669. 